\title{
New Associate Editor
}

\section{J. Malek}

Received: 2 November 2010/Accepted: 3 November 2010/Published online: 14 December 2010

(C) Akadémiai Kiadó, Budapest, Hungary 2010

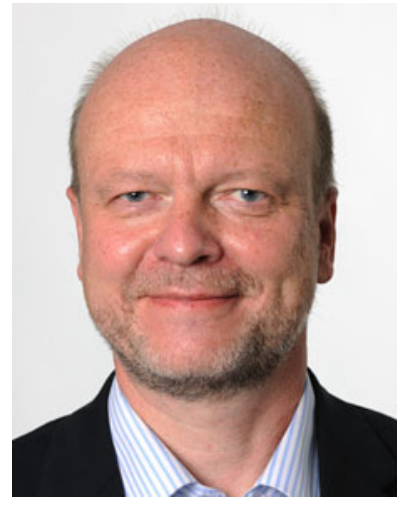

Jiri Málek received his M.Eng. and Ph.D. degrees from Department of General and Inorganic Chemistry, Institute of Chemical Technology Pardubice in 1982 and 1986 specializing in thermal behavior of non-crystalline materials. He is currently professor of Physical Chemistry at
University of Pardubice, where he has been teaching Calorimetry and Thermal analysis at the undergraduated and postgraduate levels. He spent two years as a visiting researcher at the National Institute for Materials Science, Tsukuba, Japan, two years at the University of Sevilla, and one year at the University of Catalunya, Spain. His research interests cover kinetics of solid-state processes, nucleation-growth processes in amorphous materials, structural relaxation and visco-elastic behavior of noncrystalline materials, and highly supercooled glass-forming liquids, nanostructured oxidic materials, and phase change materials, with more than 110 papers published. In 2000, he was awarded D.Sc. degree from the Institute of Chemical Technology in Prague. He is a fellow of Engineering Academy of the Czech Republic (EACR), member of the scientific board of the Czech Science Foundation (CSF), and member of the Council of International Confederation for Thermal Analysis and Calorimetry (ICTAC).

J. Malek $(\square)$

University of Pardubice, Studentska 573, 53210 Pardubice,

Czech Republic

e-mail: jiri.malek@upce.cz 